\title{
PROFILE OF STUDENTS' JUSTIFICATIONS OF MATHEMATICAL ARGUMENTATION
}

\author{
Sukirwan $^{1}$, Dedi Muhtadi ${ }^{2}$, Hairul Saleh ${ }^{3}$, Warsito $^{3}$ \\ ${ }^{1}$ Universitas Sultan Ageng Tirtayasa, Indonesia \\ ${ }^{2}$ Universitas Siliwangi, Indonesia \\ ${ }^{3}$ Universitas Muhammadiyah Tangerang, Indonesia
}

\begin{tabular}{l}
\hline \hline Article Info \\
\hline Article history: \\
Received Apr 10, 2020 \\
Revised Sep 12, 2020 \\
Accepted Sep 13, 2020 \\
\hline
\end{tabular}

\section{Keywords:}

Mathematical argumentation, Type of argument, Justifying to argument, Claim

\begin{abstract}
This study investigates the aspects that influence students' justification of the four types of arguments constructed by students, namely: inductive, algebraic, visual, and perceptual. A grounded theory type qualitative approach was chosen to investigate the emergence of the four types of arguments and how the characteristics of students from each type justify the arguments constructed. Four people from 75 students were involved in the interview after previously getting a test of mathematical argumentation. The results of the study found that three factors influenced students' justification for mathematical arguments, namely: students' understanding of claims, treatment given, and facts found in arguments. Claims influence the way students construct arguments, but facts in arguments are the primary consideration for students in choosing convincing arguments compared to representations. Also, factor treatment turns out to change students' decisions in choosing arguments, and these changes tend to lead to more formal arguments.
\end{abstract}

Copyright $(2020$ IKIP Siliwangi. All rights reserved.

\section{Corresponding Author:}

Dedi Muhtadi,

Department of Mathematics Education,

Universitas Siliwangi,

Jl. Siliwangi No.24, Tasikmalaya, West Java 46115, Indonesia

Email: dedimuhtadi@unsil.ac.id

\section{How to Cite:}

Sukirwan, S., Muhtadi, D., Saleh, H., \& Warsito, W. (2020). Profile of students' justifications of mathematical argumentation. Infinity, 9(2), 197-212.

\section{INTRODUCTION}

The National Council of Teacher Mathematics (NCTM, 2000; 2014) recommends proof as a fundamental mathematical aspect that should be studied at all levels of education. Unfortunately, the clear proof is only being studied at the high school level. Not surprisingly, when students are faced with proof, students experience many difficulties, as if the proof is a new learning and separate from the knowledge gained by previous students. It has triggered a variety of criticisms from many circles, which then encourage experts to think hard about how the proof should be taught to students (Sukirwan et al., 2017). In this case, the proof should be a process, and human activity (Stylianides \& Stylianides, 2006), meaning that every effort produced for the construction of proof cannot be ignored. These efforts then 
encourage the importance of mathematical arguments that are considered capable of bridging between formal argumentation and proof (Hidayat et al., 2018; Pedemonte, 2008).

Rumsey \& Langrall (2016) reveals that argumentation is a process of social discourse to find new mathematical ideas to convince the truth of a claim. The form of argumentation is an argument, namely the reason or several reasons offered in rejecting or accepting propositions or claims (Douek, 1999). Wood (1999) calls argumentation as one type of social interaction, meaning that there is an interactive process in the exchange of discourse. In this case, argumentation is not only oriented towards the product produced but how to create a mathematical discourse process. Thus the factors that influence the mathematical discourse process will determine the mathematical arguments produced.

What will be constructed in an argument can come from claims. Claims can be viewed as mathematical statements constructed to provide confidence to the audience based on data (Erduran et al., 2004). Data is the foundation on which arguments are based on facts that are relevant to claims. To accept or reject claims warrant (Aberdein, 2009), which describes data into a collection of premises until a conclusion is obtained (Spector \& Park, 2012). The extent of the warrant's power in deciphering data depends on the perspective used, both empirically and theoretically, even formal or informal (Freeman, 2005). Therefore, a review of the warrant has broad implications and is the basis for accommodating each of the arguments produced.

Viholainen (2011) once revealed that warrant could take various types of statements, either in the form of explanations or general statements in the form of formal or informal. In this context, the warrant is very open to formal and informal arguments. War flexibility allows students to justify, conjecturing, and generalizing (Lin, 2018), meaning that students have the opportunity to construct arguments without being fixed on rigid mathematical rules. As such, students also have the opportunity to raise criticism of their arguments, thus opening the space to more formal arguments.

Several studies on argumentation have been carried out and become a trend in reforming international mathematics education (Inglis et al., 2007; OECD, 2015). The study took different formats and constructs. At least there are three types of argumentation studies, namely: structure of argumentation, the taxonomy of proof schemes, and types of argumentation. Studies on the structure of argumentation study the schema of argumentation constructed by students, identified as data, warrant, backing, qualifier capital, rebbutal, and conclusion (Toulmin, 2003; Zarębski, 2009). Studies on the taxonomy of proof schemes identify arguments constructed by students based on abstraction levels (Bergqvist, 2005; Harel \& Sowder, 1998; Stylianides \& Stylianides, 2009; Varghese, 2011). Both of these studies have the same characteristics, namely seeing argumentation as a product. Behind that, both are still very strict on axiomatic systems so that if applied to different situations, there are chances that certain stages will not be fulfilled. Studies on the type of argumentation identify emerging mathematical representations (Healy \& Hoyles, 2000). Although both are oriented towards argumentation as a product, this study appears more flexible and open. This study also accommodates the slightest amount of students' work in constructing arguments, so that product argument is not fixed on rigid argumentation schemes. Liua et al. (2016) even use mathematical representation to see the justification of students for argumentation. The result is that students have different views on convincing arguments. Also, the tendency of students to argue with inductive patterns shows that students' habits in using arithmetic calculations, and routine algorithms still have a significant influence on student argumentation.

From various studies of argumentation, students' discourse in producing arguments seems to be the most critical part of the study of argumentation. In this regard, two frameworks can be built, namely: how to accommodate every argument constructed by 
students and how to encourage students towards more formal arguments to bridge students towards learning scientific proof. These two frameworks open the space for the importance of a review of argumentation as a process, which today is an essential part of mathematics learning (Lin, 2018; Rumsey \& Langrall, 2016). Studies on the type of argumentation and justification of students for argumentation basically can accommodate these two frameworks, but the fundamental thing that is not less important is understanding the factors that influence students' justification of argumentation. These results are ideally expected to provide input on the pedagogical actions needed for the process of mathematical argumentation.

\section{METHOD}

This study involved 75 eighth grade students who came from 2 different schools in Tangerang City, Banten Province in 2019. From each school, one class was taken which was considered the most appropriate as the research sample compared to other classes because it was considered more mature in terms of research. think and have adapted to the school environment for longer. Piaget (Liua et al., 2016), revealed that students at this level are in a critical cognitive phase where they can start to be involved in abstract and logical thinking. Besides, activities that are not disturbed by preparation for final school exams are also a consideration in this study.

A qualitative approach is used to examine students' arguments that arise from the results of mathematical argumentation tests (Creswell, 2009). In this phase, students' arguments have not been identified, only coding $\arg 1, \arg 2, \arg 3$, and so on. To identify these arguments, grounded theory is selected through the stages of open coding, selective coding, and theoretical coding (Jones \& Alony, 2011). The open coding stage is the stage of analyzing the arguments that arise based on aspects of visualization, representation, mathematical expression, how to conclude, presenting context, and so on. Meanwhile, at the selective coding stage, several student samples were selected to be followed up in interviews. Theoretical sampling is carried out based on the need for supporting data to determine the similarities and differences in information that support theory formation (Creswell, 2009). This stage determines the identification and justification of students' mathematical arguments constructed in the theoretical coding stage. Guidelines for identification of students' full mathematical arguments can be seen in Table 1.

Table 1. Giving code to emerging arguments

\begin{tabular}{ccl}
\hline Coding & Identity & \multicolumn{1}{c}{ Meaning } \\
\hline ARG 1 & Argument 1 & $\begin{array}{l}\text { The argument is stated by several examples (generally } \\
\text { numeric) that support the validity of the claims submitted }\end{array}$ \\
\hline ARG 2 & Argument 2 & $\begin{array}{l}\text { The argument is expressed from the context of symbolic } \\
\text { representations which are then represented again to support } \\
\text { the claims submitted }\end{array}$ \\
\hline ARG 3 & Argument 3 & $\begin{array}{l}\text { Arguments are expressed in graphs and images to provide an } \\
\text { explanation of the claims/conjectures submitted }\end{array}$ \\
\hline ARG 4 & Argument 4 & $\begin{array}{l}\text { An argument is expressed with a context known/imagined } \\
\text { and supported by the conjecture through a connection }\end{array}$ \\
\hline$\ldots$ & $\ldots$ & $\ldots$ \\
\hline ARG L & $\begin{array}{l}\text { Other } \\
\text { arguments }\end{array}$ & $\begin{array}{l}\text { The argument that appears and is different from arguments 1, } \\
2,3,4, \ldots . . \text { etc. }\end{array}$ \\
\hline
\end{tabular}


Data was collected through 2 main stages, namely: test mathematical arguments and interviews. In the first stage, the test is given by involving all students to construct arguments based on the statements and claims presented. The student's task is to provide an explanation of the truth of the claim or deny it. Students can agree or not to the claims submitted by including reasons or proof that support students' assessment of claims.

The test of mathematical argumentation is a test of mathematical abilities designed explicitly in the form of statements and claims. The statement contains information about claims data that can be developed into premises. Claims contain conjectures or statements that must be verified. The substance of the complete mathematical argumentation test can be seen in Table 2 .

Table 2. Mathematical argumentation test

\begin{tabular}{lll}
\hline \multicolumn{1}{c}{ Material } & \multicolumn{1}{c}{ Statement } & \multicolumn{1}{c}{ Claim } \\
\hline $\begin{array}{l}\text { Surface and } \\
\begin{array}{l}\text { Volume of } \\
\text { Cuboid }\end{array}\end{array}$ & $\begin{array}{l}\text { There are two cuboids with different } \\
\text { lengths, widths, and heights of each } \\
\text { it. After the volume is calculated, it } \\
\text { turns out that the two cuboids have an } \\
\text { equal volume }\end{array}$ & $\begin{array}{l}\text { Firman stated that although the } \\
\text { volume of the two cuboids is } \\
\text { equal, the surface must be } \\
\text { different }\end{array}$ \\
$\begin{array}{lll}\text { The volume } \\
\text { of a } \\
\text { rectangular } \\
\text { pyramid }\end{array}$ & $\begin{array}{l}\text { In the QRST.UVWX cube there is a } \\
\text { quadrilateral P.QRST as shown in the } \\
\text { picture below. }\end{array}$ & $\begin{array}{l}\text { Dudu suspects that the volume of } \\
\text { the P.QRST pyramid is two times } \\
\text { larger than the volume of } \\
\text { P.QTXU! }\end{array}$ \\
\hline
\end{tabular}

In the second stage, interviews were conducted involving some students selected based on theoretical samples. This sampling is carried out based on the consideration of representations of different types of arguments, the complexity of student answers, and other matters that arise and need to be further confirmed. While the purpose of the interview is to confirm the students' answers so that there is the relevance between the analysis of the answers predicted with the answers to the answers intended by the actual students. Also, to get further information about students 'beliefs about argumentation, in-depth interviews were conducted on aspects related to students' understanding of the mathematical concepts used, comparing the types of arguments constructed, and the possibility of students to maintain arguments.

\section{RESULT AND DISCUSSION}

\subsection{Profile of students' mathematical arguments}

In the mathematical argumentation test, students' different arguments are grouped into argument 1 , argument 2 , argument 3 , argument 4 , and other arguments. The complete grouping results of these arguments can be seen in Table 3 .

Table 3. Results of the mathematical argument test

\begin{tabular}{cccccc}
\hline \multirow{2}{*}{ Coding } & \multirow{2}{*}{ Name } & \multicolumn{2}{c}{ Conjecture 1 } & \multicolumn{2}{c}{ Conjecture 2 } \\
\cline { 3 - 6 } & & $\mathrm{N}$ & $\%$ & $\mathrm{~N}$ & $\%$ \\
\hline ARG 1 & Argument 1 & 26 & 34.67 & 16 & 21.33 \\
ARG 2 & Argument 2 & 10 & 13,33 & 12 & 16.00 \\
\hline ARG 3 & Argument 3 & 3 & 4.00 & 9 & 12.00
\end{tabular}




\begin{tabular}{clcccc}
\hline \multirow{2}{*}{ Coding } & \multirow{2}{*}{ Name } & \multicolumn{2}{c}{ Conjecture 1 } & \multicolumn{2}{c}{ Conjecture 2 } \\
\cline { 3 - 6 } & & $\mathrm{N}$ & $\%$ & $\mathrm{~N}$ & $\%$ \\
\hline ARG 4 & Argument 4 & 2 & 2.67 & 0 & 0.00 \\
ARG L & Other arguments & 2 & 2.67 & 0 & 0.00 \\
NA & Not appear & 32 & 42.67 & 38 & 50.67 \\
\hline
\end{tabular}

In Table 3, it appears that the arguments constructed by students are quite varied. In conjecture 1, there are 26 student arguments grouped into argument 1 . Whereas in conjecture 2 there are 16 student arguments grouped into argument 2. Argument 1 is the argument that appears the most among other arguments. Even so, the incidence of this argument is still low when compared to students who do not argue (NA). There were 32 students or $42.67 \%$ of students in conjecture 1 whose arguments did not appear, while 38 students, or $50.67 \%$ of students in conjecture 2 had no arguments. This shows that in general students still have difficulty making claims so that they become valid arguments.

A total of 10 students in conjecture 1 were identified as argument 2, and as many as 12 students in conjecture 2 were identified as argument 2. This number is less when compared to argument 1, but still more when compared to arguments 3 and 4 . Even in conjecture 2 argument 4 does not appear at all. In conjecture 1, 2 students are identified differently with arguments 1, 2, 3, and 4. To explore the different constructs of each of these arguments, the following is presented the students' arguments from each type of argument identified as well as the mathematical expressions constructed by students.

\subsubsection{Argument 1}

In argument 1, students use several case examples to prove the conjecture. An example of a student's answer to the two conjectures identified as argument 1 , can be seen in Figure 1.

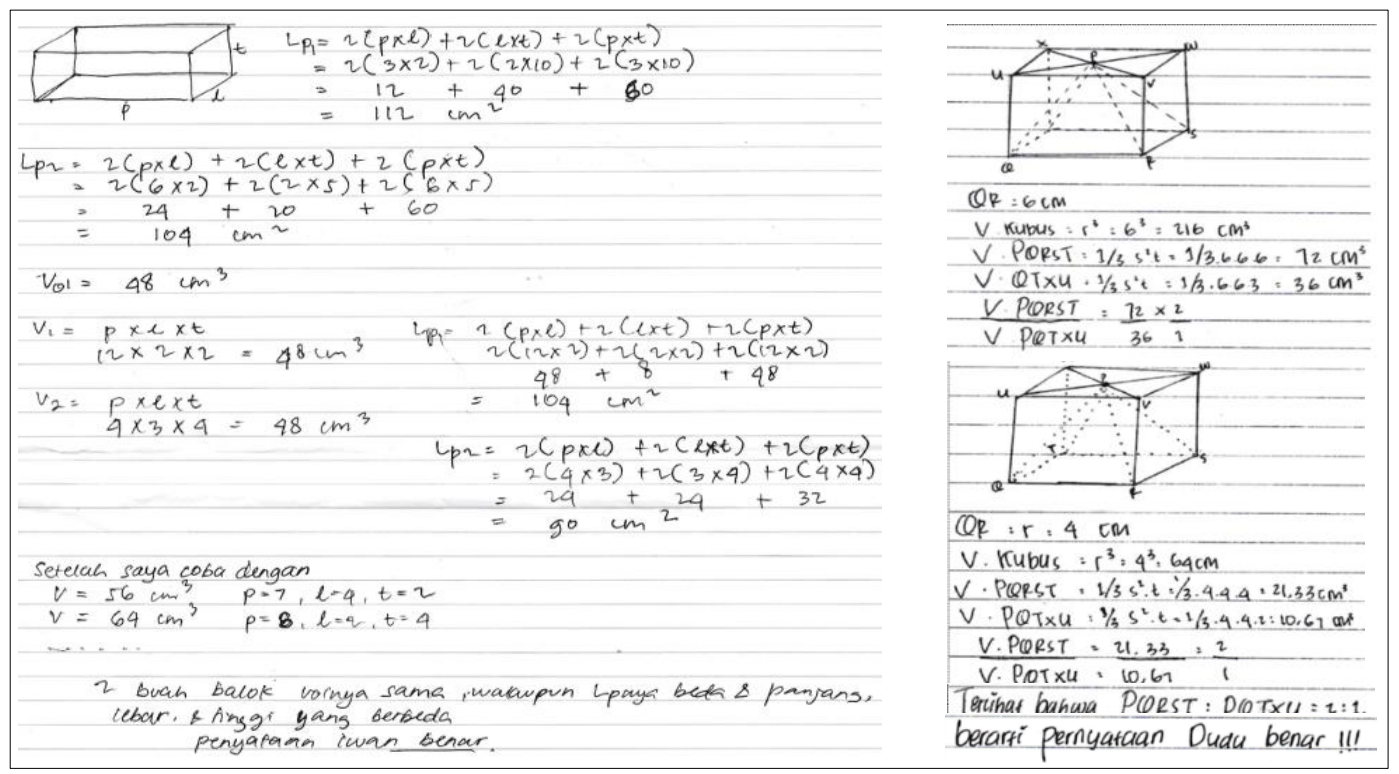

Figure 1. Yumna's and Puteri's arguments in conjecture 1 and 2, type 1 
Yumna and Putri have the same pattern in constructing arguments. Both start the argument by displaying numeric data from units of known mathematical object elements. In conjecture 1, Yumna presents 4 case examples with two primary case examples. The first case example is specifying two cuboids with the same volume, which is $60 \mathrm{~cm}^{3}$ with the size of the ribs of each cuboid $\{(3,2,10),(6,2,5)\}$. Yumna found that the surface area of the two cuboids was different, namely: $112 \mathrm{~cm}^{2}$ for the first cuboid, and $104 \mathrm{~cm}^{2}$ for the second cuboid. This result shows the fact that the claim proved correct. The second case example is specifying two cuboids with the same volume, which is $48 \mathrm{~cm}^{3}$. Yumna sets the size of the ribs of the two cuboids, respectively $\{(12,2,2),(4,3,4)\}$. Once calculated, the surface area of the two cuboids turns out to be different, namely: $104 \mathrm{~cm}^{2}$ for the first cuboid, and $90 \mathrm{~cm}^{2}$ for the second cuboid. The second fact shows that the claim is proven correct. Yumna then submitted a conjecture that the claim would be proven correct for another case with a volume of $56 \mathrm{~cm}^{3}, 64 \mathrm{~cm}^{3}$, etc. Because claims are proven correct for each case sample taken, the claim is generally valid. So the conjecture proved correct.

In conjecture 2, Putri presents 2 case examples to show that the comparison of the volume of pyramid P.QRST with the volume of P.QTXU's pyramid is 2: 1. For the first case, suppose that the ribs of the QRST.UVWX cube is $6 \mathrm{~cm}$. The P.QRST and P.QTXU pyramid are inside the QRST.UVWX cube where P, QRST, and QTXU are located on the sides of the cube. Putri calculated the volume of each pyramid so that the volume of the P.QRST pyramid was obtained at $72 \mathrm{~cm}^{3}$, and the volume of the P.QTXU pyramid was $36 \mathrm{~cm}^{3}$. The results of this calculation show that the comparison of the volume of the pyramid of P.QRST with the volume of the P.QTXU pyramid is 2: 1. For the second case, suppose that the ribs of the QRST.UVWX cube is $4 \mathrm{~cm}$. The volume of the P.QRST pyramid is $21.33 \mathrm{~cm}^{3}$, and the volume of the P.QTXU pyramid is $10.67 \mathrm{~cm}^{3}$. The results of this calculation also show that the comparison of the volume of the P.QRST pyramid with the P.QTXU pyramid volume is 2: 1. Based on the facts of the two case examples, Putri concludes that the comparison of the volume of pyramid P.QRST with the volume of P.QTXU's pyramid is 2: 1 .

\subsubsection{Argument 2}

In argument 2, symbolic representations appear by presenting arbitrary elements of mathematical objects. The elements of this mathematical object are known as data from claims. Data is then described in a mathematical model involving algebraic operations. If the results of the algebraic operation indicate that the claim can be proven, then the conjecture is correct. However, if there is only one case that shows a denial of claims, then the conjecture is wrong. Sometimes proof of claims through direct algebraic operations cannot be made. In this condition, the truth or denial of an invisible claim is indicated by the results of the algebraic operation at the deadlock. To overcome this, the claim statement can be changed into a contradictory statement, so that its denial can indicate the truth of the claim. The following are examples of student arguments that are identified as arguments 2 (see Figure 2). 


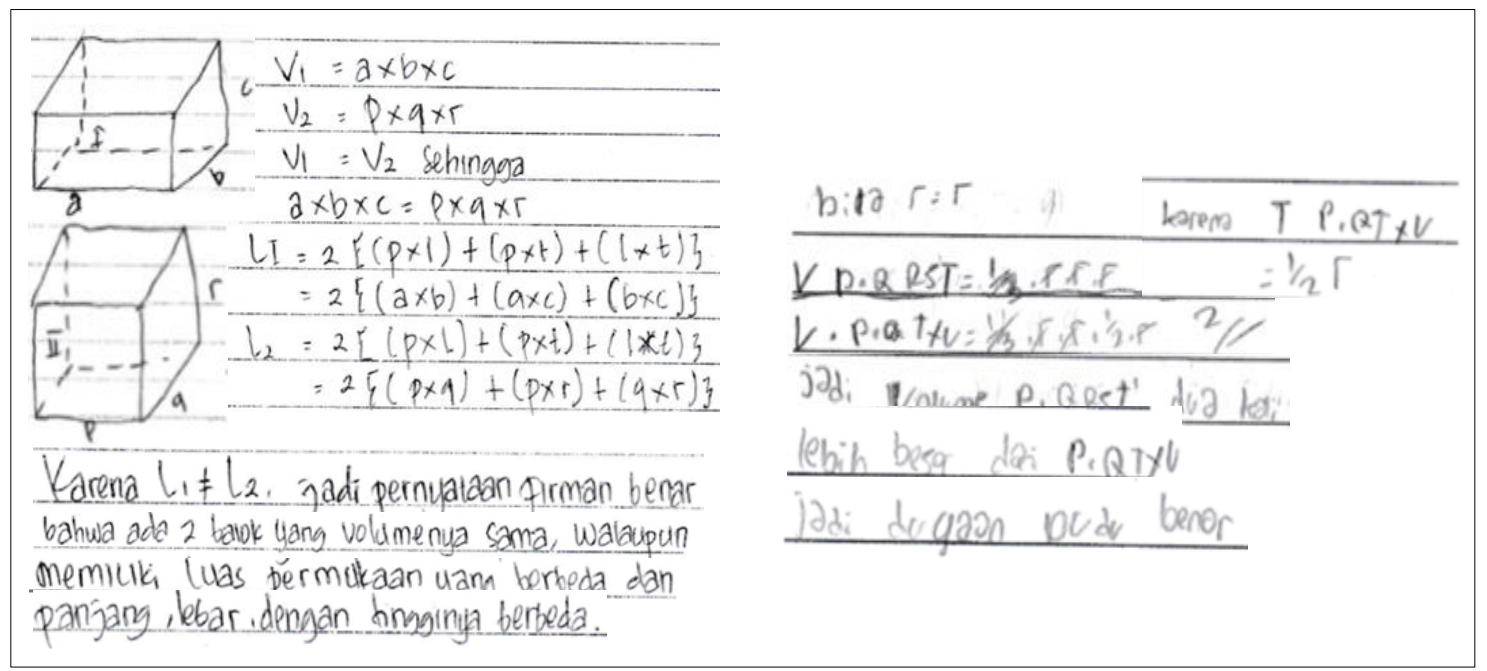

Figure 2. Arguments of Rifa and Yusuf in conjecture 1 and 2, type 2

In principle, the argument constructed by Rifa is identical to the argument that Joseph constructed. It is just that the arguments constructed by Rifa do not arrive at a claim, so the conclusion taken is incorrect. This is evident when Rifa concludes $\mathrm{L} 1 \neq \mathrm{L} 2$ without showing that $2\{(\mathrm{ab})+(\mathrm{ac})+(\mathrm{bc})\} \neq 2\{(\mathrm{pq})+(\mathrm{pr})+(\mathrm{qr})\}$ or $\{(\mathrm{ab})+(\mathrm{ac})+(\mathrm{bc})\} \neq\{(\mathrm{pq})+(\mathrm{pr})+$ (qr). The $\mathrm{L} 1 \neq \mathrm{L} 2$ statement is an argument that will be proven, based on the previous set of arguments. Because the L1 and L2 statements simultaneously do not lead to proof of the inequality of the surface area of the cuboid, then direct proof becomes difficult to express explicitly. Alternatively, contradictory proof can be used by assuming L1 $=\mathrm{L} 2$. Related to this, Rifa seems to have not understood the statement, so that at that stage, she suffered a deadlock. Although the arguments Rifa did were not complete, the algebraic features in Rifa's argument were apparent (see Figure 2). This fact also shows that algebraic arguments are more complex than previous arguments. Besides, the use of formal arguments has begun to appear with deductive principles applied.

In conjecture 3, Yusuf begins the construction of the data by declaring any PQRS.TUVW cube ribs. I am taking the $r$ symbol to declare any rib of the PQRS.TUVW cube is the starting point in the use of symbolic representations. This statement was then represented again through the use of the quadrilateral pyramid formula so that the comparison of the volume of pyramid P.QRST with the volume of the P.QTXU pyramid was obtained by 2: 1. Joseph's argument is evident with direct proof, even though the context is still elementary.

\subsubsection{Argument 3}

Argument 3 contains images, tables, or graphs that are re-represented through mathematical models based on the relationship between elements in the image or the relationship between known elements in images, tables, or graphs with elements outside of images, tables, or graphs. Argument 3 can contain more flexible arguments by relying on active imagination. Therefore, the review in the context of the problem in argument 3 is very open, even though the formal notation is still used. Examples of student answers to argument three are presented in Figure 3. 


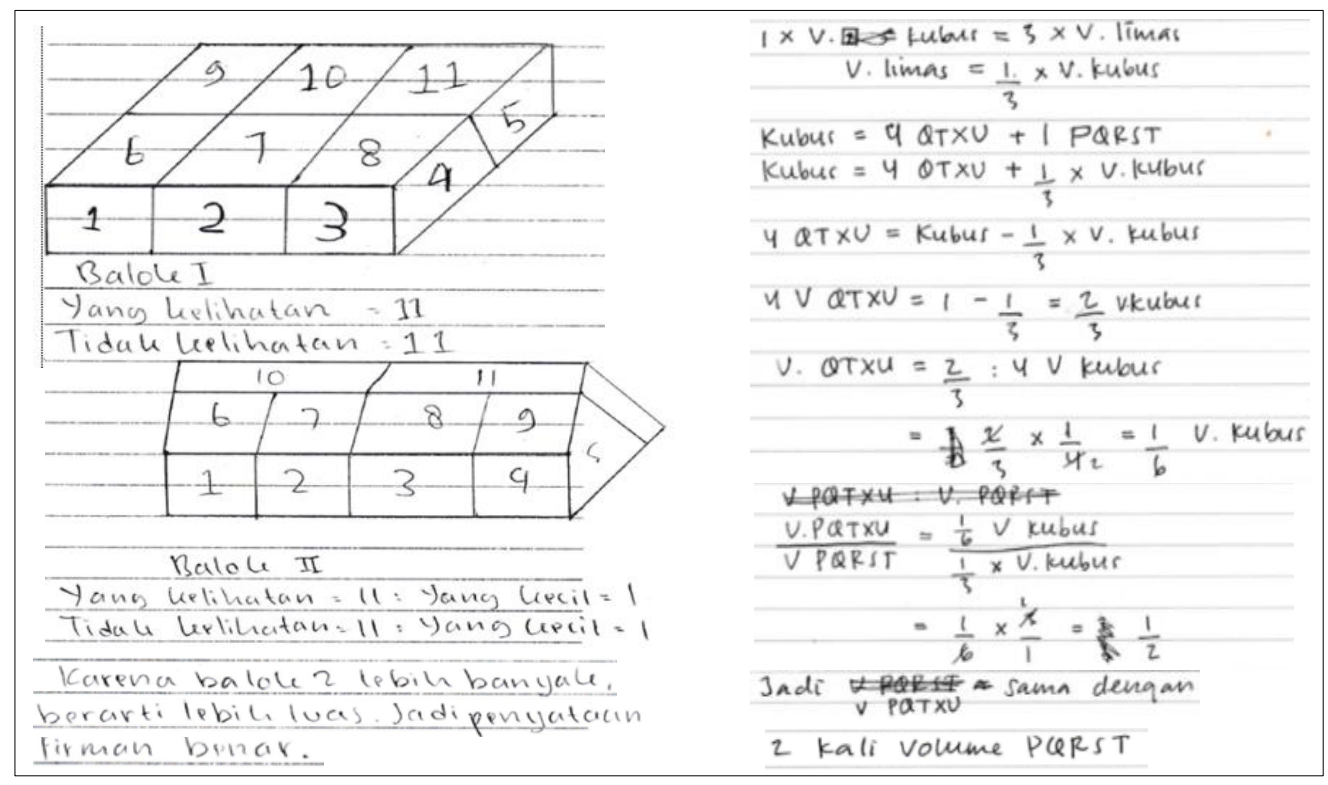

Figure 3. Irsan and Nuraida's arguments in conjecture 1 and 2, type 3

Based on Figure 3, there is a different context between Irsan's argument and Nuraida's argument. Although both rely on visual representation, Irsan tries to link the context of the cuboid to the context of the unit cube. In Irsan's argument, the cuboid partition in the unit cube - the unit cube represents the volume of the block in the unit cube (block). The small cuboid partition in the picture next refers to half a unit cube or a quarter of a unit cube, so that the volume of the cuboid is still expressed in cubes (blocks). This argument seems to be somewhat similar to an inductive argument, but the number of partitions in Irsan's argument only shows the unit volume of that partition. Thus the partition can be done arbitrarily where the volume of the cuboid is expressed as a unit of partition volume. Irsan then found that the total area of the partition on the surface of the two cuboids was different. This leads to the conclusion that the conjecture is true.

Meanwhile, Nuraida utilizes internal relations between the elements contained in the main image. Nuraida uses indirect relationships (outside the context in question) by utilizing all known elements in the main image. The complicated relationship is constructed by utilizing the conservation of volume law in which the volume of the PQRS. TUVW cube is the same as the volume of the P.QRST, P.QTXU, P.QRVU, P.RSWV, and P.STWX as the constituent elements. Because $P$ is right in the middle of the UVWX field, the P.QTXU, P.QRVU, P.RSWV, and P.STWX pyramid are congruent. If the volume of the P.QRST pyramid is $1 / 3$ the volume of the QRST cube. UVWX has been known before, then the comparison of the volume of the pyramid of P.QRST with the volume of P.QTXU's pyramid is $2: 1$.

\subsubsection{Argument 4}

Argument 4 is the least minimal argument providing information about the relationship between data and claims. This argument even requires further explanation to explain that the facts presented can be logically accepted. This argument relies on the context known in daily life as rationally acceptable as a fact that supports or denies claims. In this case, students must be good at choosing the right context so that the arguments put forward are accepted as the consensus. This work is not easy for students because not all 
mathematical concepts can be implied in the context of everyday life. Therefore, it is not surprising that the arguments that appear in this type are the fewest, not even appearing in the second conjecture. Examples of student work results on this type of argument can be seen in Figure 4.

Oua buah balok yang bentuknya berbeda, berart luas permukaannya
beda, tetapi kalau dissi beras, jumlah berasnya sama.

Figure 4. Mega's argument on conjecture 1, type 4

In Figure 4, Mega takes the context of a cuboid-shaped object. Two objects with different shapes, different surface areas. Although not entirely true, perceptually, if the shapes of the two objects are different, then the plane of the side - the corresponding side of the shape is different. Consequently, the area of the side-plane plane of the corresponding side is also different. Of course, if the corresponding pair of ribs is the same length, and it is seen that the two objects have different shapes, then the surface area of the two objects can be the same. This context does not appear to be in the perception of Mega's argument. In the next statement, if the two objects are different, can the volume be the same? This statement is difficult to perceive because taking two objects whose volume is the same is difficult. However, when a certain amount of rice is poured into the first object so that it exactly meets the object, then poured it back into the second container and exactly fulfills the object, then the two objects of the volume are the same, even though the two objects are different in shape.

\subsubsection{Other Arguments}

Early detection of other arguments shows a different pattern in the construction of the argument. This argument arises in conjecture 1. Examples of student work in this argument can be examined in Figure 5.

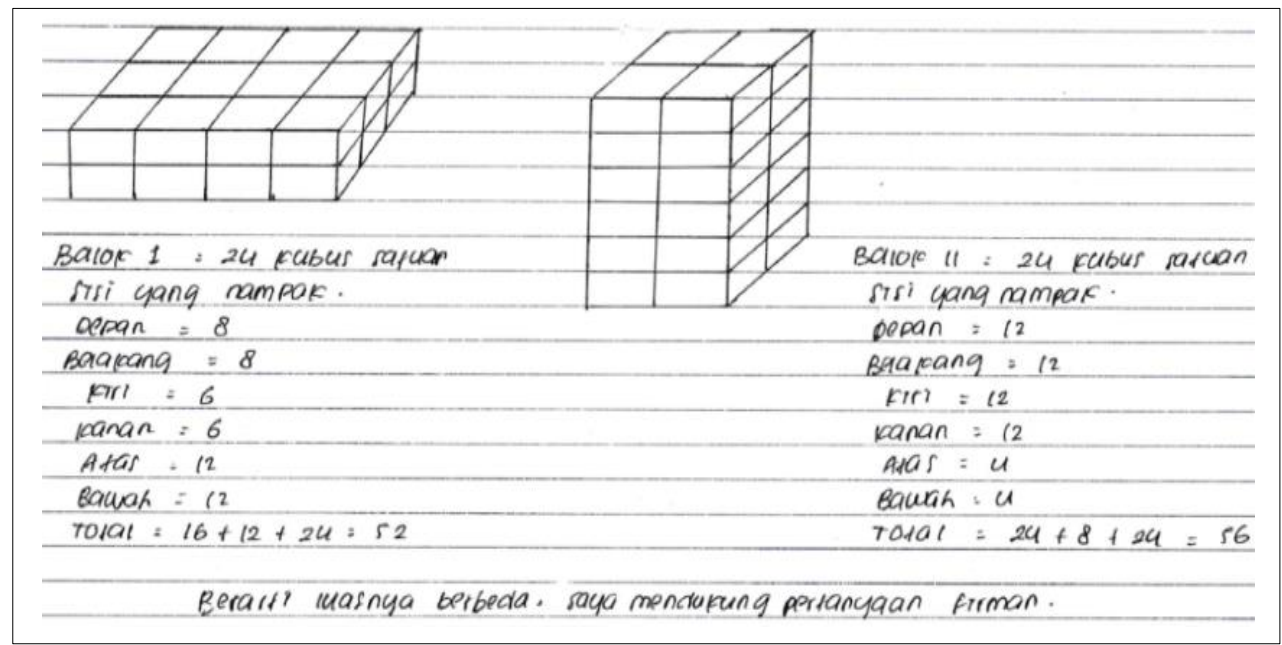

Figure 5. Yuki's Argument at conjecture 1 for the other argument 
In Figure 5, Yuki constructs an argument by presenting blocks in a unit cube (block). A total of 48 unit cubes are arranged in 2 different arrangements to form a cuboid. Each arrangement consists of 24 unit cubes. Thus, it is ensured that the two-cuboid arrangements have the same volume. The surface area of the two cuboids is then calculated based on the number of surfaces of the unit cube that appears. Yuki found a difference in the number of surface units seen between the two units of the cube. This result leads to the conclusion that Yuki took that conjecture 1 is correct.

Yuki's argument at first glance is similar to Irsan's argument. It is just that Yuki's argument is constructed based on the number of unit cubes defined from each cuboid arrangement, while Irsan's argument is constructed based on partitions performed on two cuboids with the same volume. Even though the partitions are counted, the partitions in Irsan's argument are arbitrary. Therefore, the partitions in Irsan's argument can be different in shape. Irsan's argument investigates the relationship to the parts of the image according to the characteristics of argument 3.

\subsection{Classification of Mathematical Arguments}

Classification of emerging mathematical arguments is carried out by analyzing the mathematical characteristics of each type of argument as shown in Table 1. In argument 1, students use several examples to prove claims. The student then concludes that on a more general basis the examples presented would indicate a true claim. These ways of proving such a claim appear identical to the inductive way of proof. In argument 2 , students use a more general way by presenting the argument in symbolic representations. The presentation of mathematical expressions in the form of variables indicates that the use of algebra is an option for students to show claims. In argument 3, presenting the image is the first step chosen by students to show the truth of the claim. Mathematical expressions are expressed based on the visualization of images where the proof of the truth about the claim is more real. In argument 4, students use a context that is constructed based on previous learning experiences. In this case, the mathematical expression is not presented in a formal form but uses non-formal rules that are perceived as logical. Meanwhile, other arguments that have emerged seem to still use the rules of the previous argument, so that further new categories are not created.

Based on the patterns and general characteristics that appear in arguments 1,2,3, and 4 ; These arguments are further classified as inductive arguments, algebraic arguments, visual arguments, and perceptual arguments. This method of classification is the same as that of Liu (2013) where the mathematical representations that appear in each argument that students construct are classified as inductive, algebraic, visual, and perceptual. The results of the analysis of these categories of arguments are further illustrated schematically in Figure 6.

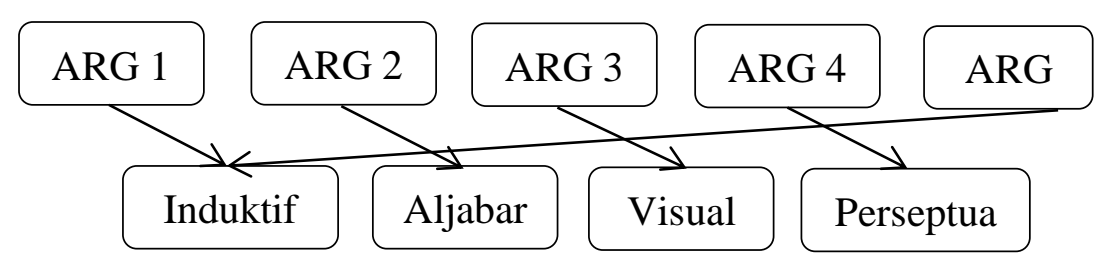

Figure 6. Argument grouping scheme based on type of argument that appears in each category 
Referring to the variations that arise from each argument, three main characteristics must be further confirmed, namely: (1) student decisions in generating convincing arguments, (2) completeness of arguments, and (3) and mathematical concepts understood in every argument. These three characteristics become the essential foundation for knowing the factors that influence students' justification for the constructs of their arguments.

\subsection{Students' Justification of Mathematical Arguments}

The deepening of the core categories is done by in-depth interviews with theoretical samples that represent the emergence of each argument. The interview refers to the three main characteristics that will be confirmed. The first characteristic is related to students' decisions in making convincing arguments. In constructing arguments, students should not necessarily use certain mathematical representations. Students must have a reason to decide that the argument they construct can explain the claim correctly. The following interview quotes provide an overview of students' decisions in using certain types of arguments.

Researcher : "Why did Yumna choose this method?" [While showing the results of Yumna's work on conjecture 1]

Yumna : "At the first test, I chose argument one, sir?"

Researcher : "What way did Yumna think about being able to work on a problem like this?" Yumna : :........... [Looks confused]

Researcher : "What did Yumna think about the cuboid in the question?"

Yumna : "O ... yes. I remember because the size of the cuboid is unknown, then I set the size first."

The results of interviews with Yumna illustrate that the arguments he constructed were inspired by arguments that had been previously constructed. Students are initially asked to look at existing arguments as part of the initial treatment before the test argument is given. Yumna chooses inductive arguments based on the belief that this type of argument is most effective in explaining claims. From this explanation, Yumna obtained information that the initial treatment had a strong influence on the students' decision to choose the argument they constructed.

To complete information about a convincing choice of arguments, interviews were conducted with other students, as illustrated in the results of the following interview.

Researcher : "Is Mega thinking about two different shapes?"

Mega : "I imagine two containers in the form of cuboids; the shape is different."

Researcher : "What kind of container, for example?"

Mega : "The main thing is made of plastic."

Researcher : "Where is Mega, sure that the two containers are different?"

Mega : "Yes, from the ribs, sir. For example, one container six, four, two, one another four, four, three."

Researcher : "Why doesn't Mega write like that?"

Mega : "That, the argument is different, right, sir."

Researcher : "Okay. Is the argument more convincing? "

Mega : "Actually, yes, sir."

Researcher : "Why not choose that argument?"

Mega : "At that time, I understood the argument four more, which in that example." 
The quote from the interview with Mega illustrates that treatment influences students' beliefs about arguments. This belief can also change when more convincing arguments are found. In other words, students are not consistent with the choice of arguments and tend to change along with the treatment given.

The characteristics of the next student's answer are the completeness of the argument. The characteristics of this answer are also related to mathematical concepts that are understood in every argument constructed by students. Understanding of mathematical concepts is the main thing that influences student arguments, as illustrated in the following interview excerpt.

Researcher : "What is Rifa's opinion about this conjecture 1?"

Rifa : "It's a general problem, sir."

Researcher : "I mean."

Rifa : "The sizes are unknown, so the proof is also arbitrary."

Researcher : "Why aren't the ribs replaced with numbers?"

Rifa : "If the numbers only apply to certain blocks?"

Researcher : "Okay, is Rifa's answer, complete?"

Rifa : "I'm stuck here, sir" [While pointing at the answer sheet]

Researcher : "Why not suppose that Lone is not equal to L two."

Rifa : :Don't understand, sir?"

Rifa understands that conjecture is a general statement. Rifa considers that claims cannot be shown by a particular case, because the example only applies to that problem. It seems that Rifa is not affected by the treatment given. This indicates that students in the formal category tend to defend their arguments. Even so, Rifa is not complete in constructing his argument. Rifa does not seem to understand the ways to prove a statement, for example, by counterexample.

Rifa's opinion on the argument shows that students' understanding of claims influences the way students argue. Students will try to prove the argument if the claim is understood correctly. Understanding of claims will then influence the mathematical concepts described in the premises until a conclusion is obtained.

In addition to understanding the claims, the facts in the argument also influence students' justification of arguments. This was revealed from the results of the following interview.

Researcher : "Why did the Putri choose this method to solve the problem?"

Puteri : "That's what I understand, sir."

Researcher : "Are other arguments not understood? Suppose this argument "[refers to an algebraic argument]

Puteri : : "Understood, too, sir. But if the ribs are determined it will be clearer."

Researcher : "What about the other arguments?"

Puteri : "Understood that too. But the important thing is proven, right, sir."

Women's opinion shows that facts that show the truth of claims are one of the factors that influence the argument. The Putri does not care about the representation that appears in certain arguments. The important thing is how the argument can show the truth of the claim. This is by the findings of previous research that the fact in the argument has a greater 
influence than the mathematical representation.

The results of the interviews with the four students showed that the tendency of students to choose inductive arguments was more open than other arguments. This is relevant to the research of Liua et al. (2016) where the inductive way is the easiest to understand to explain the claim. Another case with Bergqvist (2005) where teachers in Sweden underestimate students to use non-formal methods rather than formal methods. The findings of this study are relatively the same as Berqvist's research, where the facts about the use of formal mathematics were chosen by students more than non-formal mathematics. It is interesting to explore in this study that students are always interested in changing their arguments into more formal arguments. Argumentation may become a bridge for more formal mathematics learning, especially mathematical proof. As recommended by Pedemonte (2008) about the cognitive unity hypothesis that allows students to learn mathematical evidence through mathematical argumentation.

\section{CONCLUSION}

Based on the results of the research described in the result and discussion, it can be stated that the mathematical arguments constructed by students include four types of arguments, namely: inductive, algebraic, visual, and perceptual. The inductive argument presents several examples of cases which are then generalized. This argument also relies on numerical representation in strengthening the facts in a case example. The algebraic argument presents symbolic representation by specifying several elements of mathematical objects that are known arbitrarily. Formal notation in this argument has also been seen by giving rise to a deductive approach. The visual argument presents images, tables, or graphs that are represented again in mathematical or visual models. This argument also relies on the relationship between elements in images or between images and contexts outside the image so that a mathematical model is obtained. The perceptual argument presents a known context that logically can be accepted as a fact that supports or denies claims. But because perceptions of the context can be different, the information in context sometimes needs to be explained further.

Three factors influence the justification of students for mathematical arguments, namely: students' understanding of proven claims, treatment given, and facts found in the argument. Giving treatments is the main factor influencing justification. Treatment even affects students' decisions in choosing arguments. These changes tend to lead to more formal arguments. Behind that, students are also always interested in changing their mathematical arguments into arguments that are considered the most relevant for proving claims and leading to formal arguments.

\section{ACKNOWLEDGMENTS}

The authors would like to thank the teachers and students who participated in this research.

\section{REFERENCES}

Aberdein, A. (2009). Mathematics and argumentation. Foundations of Science, 14(1), 1-8. https://doi.org/10.1007/s10699-008-9158-3

Bergqvist, T. (2005). How students verify conjectures: Teachers' expectations. Journal of Mathematics Teacher Education, 8(1), 171-191. https://doi.org/10.1007/s10857-0054797-6 
Creswell, J. W. (2009). Research design: Qualitative, quantitative, and mixed methods approaches. Sage publications.

Douek, N. (1999). Argumentation and conceptualization in context: A case study on sun shadows in primary school. Educational Studies in Mathematics, 39(1/3), 89-110. https://doi.org/10.1023/a:1003800814251

Erduran, S., Simon, S., \& Osborne, J. (2004). TAPping into argumentation: Developments in the application of Toulmin's Argument Pattern for studying science discourse. Science Education, 88(6), 915-933. https://doi.org/10.1002/sce.20012

Freeman, J. B. (2005). Systematizing Toulmin's warrants: An epistemic approach. Argumentation, 19(3), 331-346. https://doi.org/10.1007/s10503-005-4420-0

Harel, G., \& Sowder, L. (1998). Students' proof schemes: Results from exploratory studies. In A. H. Schoenfeld, J. Kaput, \& E. Dubinsky (Eds.), Research in Collegiate Mathematics Education, 234-283. https://doi.org/10.1090/cbmath/007/07

Healy, L., \& Hoyles, C. (2000). A study of proof conceptions in algebra. Journal for Research in Mathematics Education, 31(4), 396-428. https://doi.org/10.2307/749651

Hidayat, W., Wahyudin, W., \& Prabawanto, S. (2018). The mathematical argumentation ability and adversity quotient (AQ) of pre-service mathematics teacher. Journal on Mathematics Education, 9(2), 239-248. https://doi.org/10.22342/jme.9.2.5385.239248

Inglis, M., Mejia-Ramos, J. P., \& Simpson, A. (2007). Modeling mathematical argumentation: The importance of qualification. Educational Studies in Mathematics, 66(1), 3-21. https://doi.org/10.1007/s10649-006-9059-8

Jones, M., \& Alony, I. (2011). Guiding the use of grounded theory in doctoral studies - an example from the Australian film industry. International Journal of Doctoral Studies, $6,95-114$.

Lin, P.-J. (2018). Improving knowledge for teaching mathematical argumentation in primary classrooms. Journal of Mathematics Education, 11(1), 17-30. https://doi.org/10.26711/007577152790018

Liu, Y. (2013). Aspects of mathematical arguments that influence eight grade students' judgment of their validity. The Ohio State University.

Liua, Y., Tagueb, J., \& Somayajulub, R. (2016). What Do Eighth Grade Students Look for When Determining If a Mathematical Argument Is Convincing. International Electronic Journal of Mathematics Education, 11(7), 2373-2401.

NCTM. (2000). Principles and standards for school mathematics. National Council of Teachers of Mathematics.

NCTM. (2014). Principles to Actions: Ensuring Mathematical Success for All. National Council of Teachers of Mathematics.

OECD. (2015). Draft mathematics framework. The Organisation for Economic Co-operation and Development (OECD).

Pedemonte, B. (2008). Argumentation and algebraic proof. ZDM - International Journal on Mathematics Education, 40(3), 385-400. https://doi.org/10.1007/s11858-008-0085-0

Rumsey, C., \& Langrall, C. W. (2016). Promoting mathematical argumentation. Teaching Children 
https://doi.org/10.5951/teacchilmath.22.7.0412

Spector, J. M., \& Park, S. W. (2012). Argumentation, critical reasoning, and problemsolving. In S. B. Fee \& B. R. Belland (Eds.), The Role of Criticism in Understanding Problem Solving (pp. 13-33). Springer. https://doi.org/10.1007/978-1-4614-3540-2_2

Stylianides, A. J., \& Stylianides, G. J. (2006). Content knowledge for mathematics teaching: The case of reasoning and proving. In J. Novotna, H. Moraova, M. Kratka, \& N. Stehlikova (Eds.), Proceedings of the 30th Conference of the International Group for the Psychology of Mathematics Education, 5, 201-208.

Stylianides, A. J., \& Stylianides, G. J. (2009). Proof constructions and evaluations. Educational Studies in Mathematics, 72(2), 237-253. https://doi.org/10.1007/s10649009-9191-3

Sukirwan, Darhim, Herman, T., \& Prahmana, R. C. I. (2017). The students' mathematical argumentation in geometry. Journal of Physics: Conference Series, 943(1), 1-6. https://doi.org/10.1088/1742-6596/943/1/012026

Toulmin, S. E. (2003). The uses of argument: Updated edition. Cambridge University Press.

Varghese, T. (2011). Balacheff's 1988 taxonomy of mathematical proofs. Eurasia Journal of Mathematics, Science \& Technology Education, 7(3), 181-192. https://doi.org/10.12973/ejmste/75192

Viholainen, A. (2011). The view of mathematics and argumentation. In M. Pytlak, T. Rowland, \& E. Swoboda (Eds.), Proceedings of the 7th Congress of the European Society for Research in Mathematics Education, 243-252.

Wood, T. (1999). Creating a context for argument in mathematics class. Journal for Research in Mathematics Education, 30(2), 171-191. https://doi.org/10.2307/749609

Zarębski, T. (2009). Toulmin's model of argument and the logic of scientific discovery. Studies in Logic, Grammar, and Rhetoric, 16(29), 267-283. 
